\title{
Understanding Common Sense: A Personal Preface
}

\author{
Michael W. Apple \\ University of Wisconsin
}

In the often autobiographical interview with me, "Education, Power, and Personal Biography, "published in this issue, I trace my early attempts to combine social phenomenology with cultural Marxism. The integration of these perspectives-stimulated for me by my earlier grounding in the work of Schutz and Merleau-Ponty on the one hand and the perspectives of critical theory and Gramsci on the other-has led to a consistent focus in my own work. For more than two decades, I have sought to understand the formation of common sense as a social phenomenon. But common sense is not random; it is articulated around particular principles that have complex but identifiable connections to relations of power in society.

In this context, the issue of how common sense is constructed and reconstructed is really a question of the intimate relationship between knowledge and power. For me, these are part of an indissoluble couplet. As someone deeply involved in critical education, both as theory and practice, much of my work has focused on how this relationship is recreated and transformed in one set of institutions-schools. I have devoted an entire series of volumes, from Ideology and Curriculum (1979; 2 nd ed. 1990) and Education and Power (1982; 2nd ed. 1985) to Teachers and Texts (1988), to disclosing the positive and negative moments and dynamics in this couplet.

Among the questions I have asked are: Whose knowledge, whose culture, whose common sense, is made legitimate in our educational institutions? How does education function in the reproduction and subversion of cultural, political, and economic authority? How do we as educators understand these things? As you would imagine, this connection between knowledge and power is not an easy relationship to understand, in part because it shifts as new social conditions alter both the connection and our approaches to disclosing it.

In the article that follows, I continue these efforts at unpacking the ways common sense operates in relations of inequality. I am particularly interested here in how conservative movements work on the identity of people and how they shift our everyday

Phenomenology + Pedagogy Volume 81990 
perceptions to the right. The article provides an example both of the approaches I believe are so necessary to fully comprehend the ideological shifts that are occurring in the larger society and of the kinds of things I discuss in the interview. In particular, it provides the reader with more substance about my responses to the insightful questions on critical educational theory and on political movements inside and outside of education that Carlos Torres asks me during the interview. 